Bull. Mater. Sci., Vol. 3, Number 1, February 1981, pp. 1-8. (C) Printed in India.

\title{
Some barium titanate based dielectrics
}

A M VARAPRASAD*, D K CHAKRABARTY and

A B BISWAS ${ }^{\dagger}$

Solid State Laboratory, Chemistry Department, Indian Institute of Technology, Bombay 400 076, India

* Present address: Hindustan Lever Research Centre, Bombay 400093 , India

MS received 23 February 1980; revised 28 June 1980

\begin{abstract}
Some new potential dielectric materials have been made through the cross-substitution of $\mathrm{Ba}^{2+}$ by a 1:1 molar combinations of tri-( $\left(\mathrm{La}^{3+}\right)$ and mono-valent $\left(\mathrm{Li}^{+}, \mathrm{Na}^{+}, \mathrm{K}^{+}\right)$ions at the $\mathrm{Ba}^{2+}$ site in $\mathrm{BaTiO}_{3}$. Chemical analysis shows that compositions in the potassium series are about $6.1 \%$ deficient in their $\mathbf{K}_{2} \mathrm{O}$ content and exhibit interesting dielectric relaxations. The cross-substitution has lowered the $T_{c}$ down to room temperature. The disorder in the larger ' $A$ ' cation sublattice of the three systems has been established by infra-red and x-ray data. This leads to microscopic compositional variations, which in turn can account for the diffuseness of the dielectric anomalies observed in the barium titanate-rich compositions $(0 \leqslant x \leqslant 0 \cdot 3)$.
\end{abstract}

Keywords. Dielectrics; ceramics; phase transformation; barium titanate.

\section{Introduction}

Barium titanate which exhibits high dielectric constant $(\varepsilon)$ at its Curie temperature $(393 \mathrm{~K})$ is extensively used. However, it suffers from a steep variation of $\varepsilon$ with $T$ in the vicinity of $T_{v}$. For practical dielectric for capacitors it is desirable to have a material with high dielectric constant at room temperature with as small a temperature coefficient of capacitance as possible in the temperature range of interest. This can be achieved by modifying the $\mathrm{BaTiO}_{3}$ composition by alloying to shift its $T_{e}$ to room temperature and broaden the $\varepsilon-T$ curve. One of the promising systems seems to be of the type $\left(M_{1 / 2} \mathrm{La}_{1 / 2}\right)_{x} \mathrm{Ba}_{1-\infty} \mathrm{TiO}_{3}$ where $\mathrm{M}=\mathrm{Li}$, $\mathrm{Na}, \mathrm{K}$. This system is discussed in the present paper. Here the lowering of $T_{0}$ would be expected through the substitution of relatively smaller polarizable ions $\left(\mathrm{M}_{1 / 2} \mathrm{La}_{1 / 2}\right)$ in the $\mathrm{Ba}$ sites. Apart from potential technological application, the compositions are interesting from the point of view of crystal chemistry and dielectric relaxation due to vacant lattice sites.

t since deceased. 


\section{Materials preparation}

The compounds represented by $\left(\mathrm{M}_{1 / 2} \mathrm{La}_{1 / 2}\right) \mathrm{TiO}_{3}$ where $\mathrm{M}=\mathrm{Li}, \mathrm{Na}$ and $\mathrm{K}$ were prepared following the usual high temperature solid state reaction procedures. The sequence of heat treatments are as follows : Preheating at $1075 \mathrm{~K} \mathrm{for} 24 \mathrm{hr}$. Reaction treatment at $1150 \mathrm{~K}$ for $\mathrm{Li}$ and at $1225 \mathrm{~K}$ for $24 \mathrm{hr}$ for $\mathrm{Na}$ and $\mathrm{K}$. The compound $\left(\mathrm{K}_{1 / 2} \mathrm{La}_{1 / 2}\right) \mathrm{TiO}_{3}$ is found to be about $6 \cdot 1 \%$ deficient in its $\mathrm{K}_{2} \mathrm{O}$ content. Brous et al (1953) who prepared it by heating the reactants together at $1475 \mathrm{~K}$ for $1 \mathrm{hr}$ reported about $5 \%$ deficiency in $\mathrm{K}_{2} \mathrm{O}$ content. This small difference between the results (about $1 \%$ ) may be due to the difference in the preparative conditions.

\subsection{Chemical analysis}

For chemical analysis, a weighed sample of $\left(\mathrm{K}_{1 / 2} \mathrm{La}_{1 / 2}\right) \mathrm{TiO}_{3}$ (about $10 \mathrm{~g}$ ) was treated with boiling dilute nitric acid and filtered in a weighed Goosch crucible. The sample and the crucible were then dried to a constant weight. The filtrate was tested for lanthanum and titanium and these were found to be absent. The mass loss on washing can then be assumed to be entirely due to the loss of monovalent ions in the form of $\mathrm{K}_{2} \mathrm{O}$ which has not entered the crystal lattice during preparation. The possibility of some of the titanium getting reduced due to the potassium leaving the lattice may be ruled out in view of diamagnetism of the compound.

The mixed compositions were prepared by heating appropriate quantities of $\mathrm{M}_{1 / 2} \mathrm{La}_{1 / 2} \mathrm{TiO}_{3}(\mathrm{M}=\mathrm{Li}, \mathrm{Na}$ and $\mathrm{K})$ and $\mathrm{BaTiO}_{3}$ at 1150 for $\mathrm{Li}$ and at $1225 \mathrm{~K}$ in the case of $\mathrm{Na}$ and $\mathrm{K}$ for about $48 \mathrm{hr}$. An additional heating cycle at $1325 \mathrm{~K}$ for $24 \mathrm{hr}$ was required to obtain single phase compositions with $x=0.5$ and $\mathbf{0 . 7}$ in the potassium series. The samples in all cases were furnace-cooled. The pellets for dielectric measurements were sintered at $1200 \mathrm{~K}$ in case of $\mathrm{Li}$ and $1475-1525 \mathrm{~K}$ for $\mathrm{Na}$ and $\mathrm{K}$ for $4 \mathrm{hr}$. The compact densities varied in the range of 85 to $90 \%$ of the respective $\mathrm{x}$-ray density.

\section{Structural aspects}

The sodium and the potassium systems formed perovskite solid solutions over the entire range of its solid solubility $0 \leqslant x \leqslant 1 \cdot 0$. The result of the $\mathrm{x}$-ray studies are presented in table 1 . In the $\mathrm{Na}$ series, the solid solutions upto $x=\mathbf{0 . 3}$ are tetragonal and exhibit cubic symmetry beyond $x=0 \cdot 3$ (Varaprasad et al 1977). In the potassium deficient $\left(\mathrm{K}_{1 / 2} \mathrm{La}_{1 / 2}\right) \mathrm{TiO}_{3}$ system, the composition $x=0 \cdot 3$ is tetragonal and the details of $\mathrm{X}$-ray data were presented in an earlier communication (Varaprasad et al 1979). In the case of $\mathrm{Li}_{1 / 2} \mathrm{La}_{1 / 2} \mathrm{TiO}_{3}$, perovskite solid solutions are limited to the range $0 \leqslant x \leqslant 0.5$ (see table 1) due to structural incompatibility between the end members viz, $\mathrm{BaTiO}_{3}$ (perovskite) and $\mathrm{Li}_{1 / 2} \mathrm{La}_{1 / 2} \mathrm{TiO}_{3}$ (tetragonal tungsten bronze type) (Varaprasad et al 1979). It may be noted that none of the perovskite compositions contains super lattice reflections, suggesting the possibility of random cation distribution in the $A$ cationic sublattice. 
Table 1. X-ray and dielectric loss data of the system $\left(\mathrm{M}_{L / 2} \mathrm{La}_{1 / 2}\right)_{6} \mathrm{Ba}_{1-\infty} \mathrm{TiO}_{3}$.

\begin{tabular}{|c|c|c|c|c|}
\hline $\begin{array}{c}\text { Composition } \\
x\end{array}$ & Symmetry & $a \AA$ & $\mathrm{c} \AA$ & $\begin{array}{c}\tan \delta \text { at } \\
300 \mathrm{~K}\end{array}$ \\
\hline \multicolumn{5}{|l|}{ (1) $\mathrm{M}=\mathrm{Li}$} \\
\hline 0.2 & Cubic & 3.995 & $\ldots$ & 0.023 \\
\hline $0 \cdot 3$ & Cubic & $3 \cdot 986$ & .. & 0.030 \\
\hline 0.4 & Cubic & $3 \cdot 976$ & .. & $0 \cdot 035$ \\
\hline 0.5 & Cubic & $3 \cdot 975$ & . & 0.043 \\
\hline \multicolumn{5}{|l|}{ (2) $\mathrm{M}=\mathrm{Na}$} \\
\hline $0 \cdot 1$ & Tetragonal & 3.986 & $4 \cdot 033$ & 0.007 \\
\hline 0.2 & Tetragonal & $3 \cdot 960$ & $4 \cdot 010$ & 0.040 \\
\hline 0.3 & Tetragonal & $3 \cdot 941$ & $3 \cdot 990$ & 0.306 \\
\hline 0.5 & Cubic & $3 \cdot 943$ & .. & $0 \cdot 483$ \\
\hline $0 \cdot 7$ & Cubic & 3.906 & .. & 0.375 \\
\hline 0.9 & Cubic & $3 \cdot 873$ & .. & 0.420 \\
\hline $1 \cdot 0$ & Cubic & $3 \cdot 865$ & . & 0.017 \\
\hline \multicolumn{5}{|l|}{ (3) $M=K$} \\
\hline 0.1 & Cubic & 3.999 & . & 0.020 \\
\hline $0 \cdot 2$ & Cubic & 3.989 & .. & $0 \cdot 030$ \\
\hline $0 \cdot 3$ & Tetragonal & $3 \cdot 963$ & $4 \cdot 065$ & 0.033 \\
\hline 0.5 & Cubic & $3 \cdot 952$ & .. & 0.038 \\
\hline 0.7 & Cubic & $3 \cdot 912$ & .. & 0.042 \\
\hline 0.9 & Cubic & $3 \cdot 899$ & .. & 0.034 \\
\hline $1 \cdot 0$ & Cubic & $3 \cdot 894$ & .. & 0.050 \\
\hline
\end{tabular}

In the infrared spectra of the perovskites, the assymetry and broadening of the Ti-O stretching mode has been related to the disorder in the A cationic sublattice via Pauling electrostatic valency of the cations (Pauling 1960 and Blasse 1977) and has been treated in detail for the sodium system previously (Varaprasad et al 1977). The same is true for the lithium and the potassium systems too, except that the degree of disorder may be decreasing in the order $\mathrm{Li}>\mathrm{Na}>\mathrm{K}$ (Kaleveld et al 1973).

\section{Dielectric properties}

\subsection{Diffuseness of the phase transitions}

The dielectric constant ( $\varepsilon$ ) vs reciprocal temperature for the $\mathrm{Li}, \mathrm{Na}$ and $\mathrm{K}$ compositions are given in figures 1,2 and 3 respectively and the data are presented in table 1. It is seen from the figures that the cross-substitution of $\mathrm{Ba}^{2+}(a=1 \cdot 55$ $\left.\times 10^{-24} \mathrm{~cm}^{3}\right)$ by relativey less polarizable LiLa $\left(a=0.50 \times 10^{-24} \mathrm{~cm}^{3}\right)$, NaLa $\left(a=0.61 \times 10^{-24} \mathrm{~cm}^{3}\right)$ and $\mathrm{KLa}\left(a=0.93 \times 10^{-24} \mathrm{~cm}^{3}\right)$ particularly in the range $0 \leqslant x \leqslant 0.3$ has lowered the $T_{c}(393 \mathrm{~K})$ down near to room temperature except for the tetragonal composition $\left(\mathrm{K}_{1 / 2} \mathrm{La}_{1 / 2}\right)_{0 \cdot 3} \mathrm{Ba}_{0.7} \mathrm{TiO}_{3}$ which shows a dielectric peak at about $400 \mathrm{~K}$. A possible explanation for the observed anomaly in this composition is suggested in $\S 4.3$. 


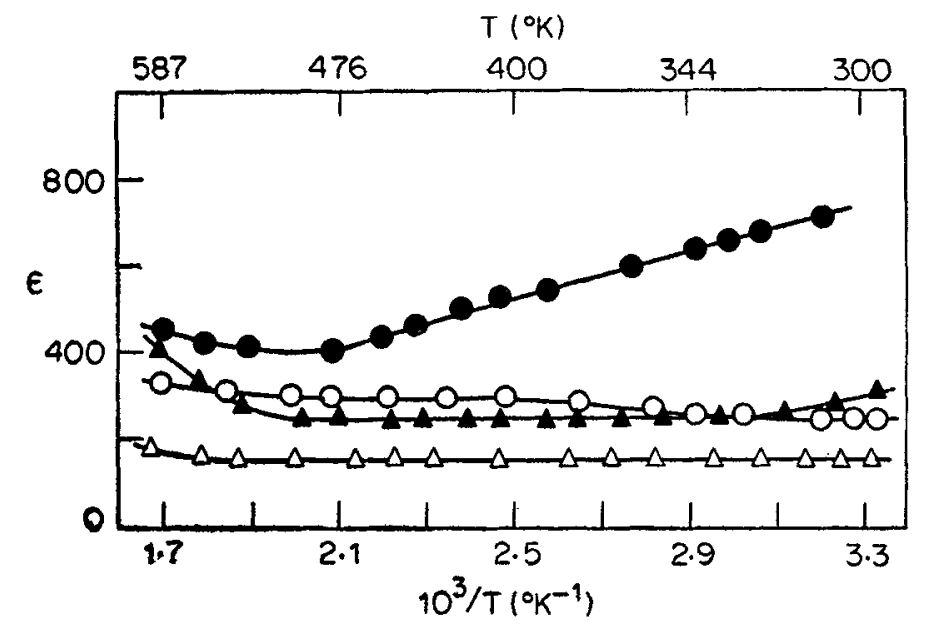

Figure 1. Dielectric constant $(\epsilon)$ versus $\left(10^{3} / T\right)$ for the system $\left(\mathrm{Li}_{1 / 2} \mathrm{La}_{1 / 2}\right)_{x} \mathrm{Ba}_{1}$. $\mathrm{TiO}_{2}$. Parameter $x: \bullet 0.2, \Delta 0.3, \Delta 0.4,00.5$.

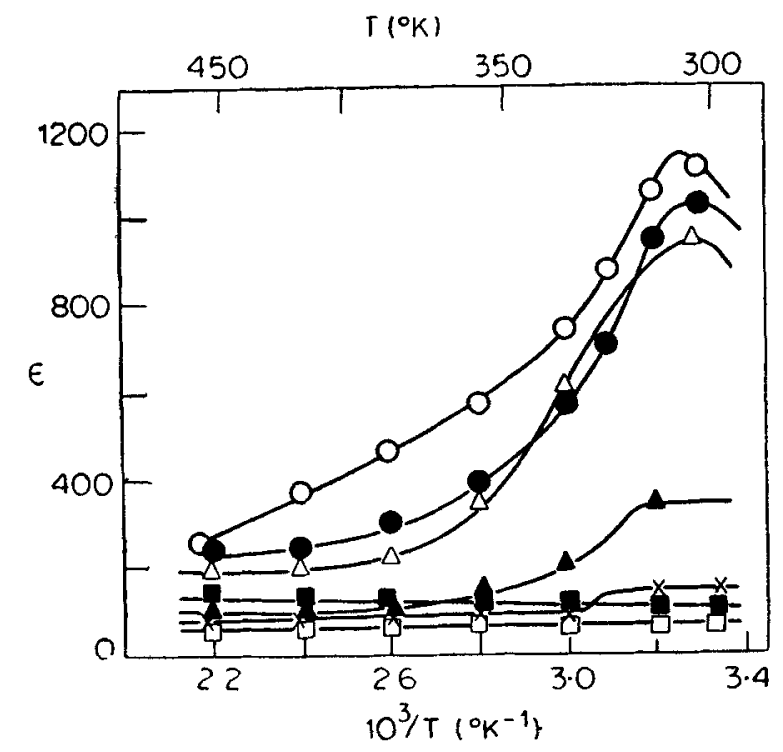

Figure 2. Dielectric constant $(\epsilon)$ versus $\left(10^{3} / T\right)$ for the system $\left(\mathrm{Na}_{1 / 2} \mathrm{La}_{1 / 2}\right)_{z} \mathrm{Ba}_{1-x}$ $\mathrm{TiO}_{3}$. Parameter $x: \circ 0.1,0.2, \Delta 0.3, \Delta 0.5, \times 0.7, \square 0.9, \square 1 \cdot 0$.

One of the striking features of the dielectric constant vs temperature plots is the broadening of the dielectric peak. Earlier, macroscopic inhomogeneities such as growth strains have been proposed to be the cause for the diffuseness of the phase transition (DPT). However, in the wake of the diffuse dielectric phenomena observed in several complex perovskite like solid solutions even in the single crystal state without growth strains (Smolensky 1970; Scott et al 1970, and Clarke and Burfoot 1974), we are led to think that there will be more important causes that give rise to diffuse dielectric phenomena, 


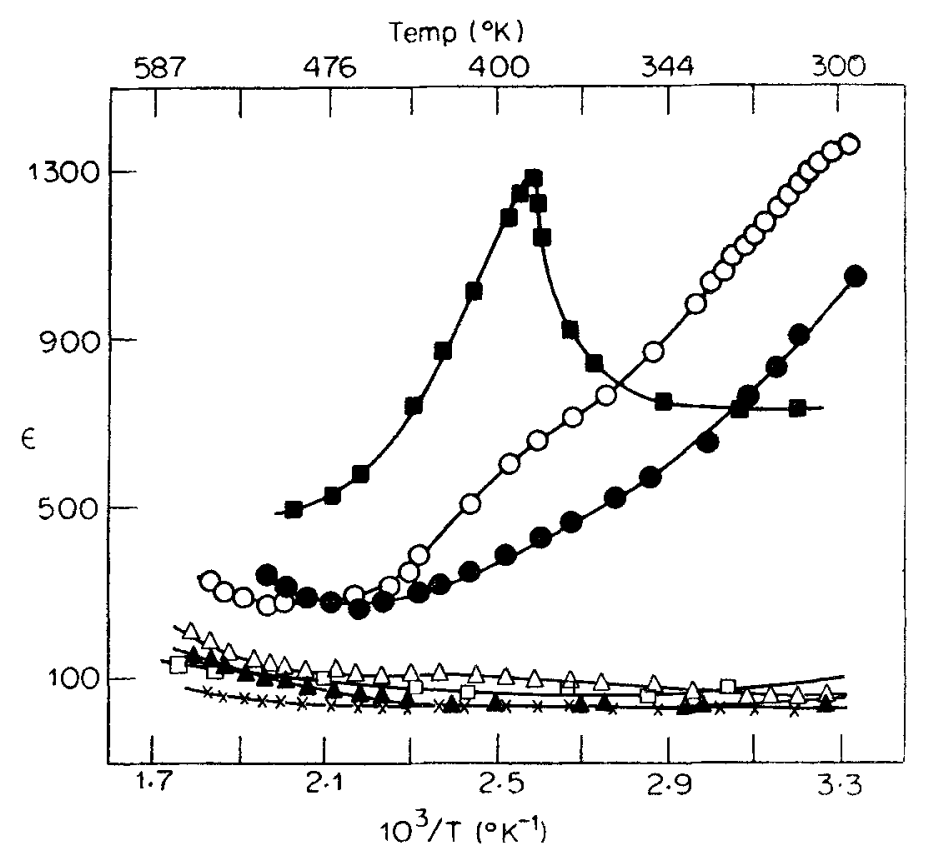

Figure 3. Dielectric constant $(\epsilon)$ versus $\left(10^{3} / T\right)$ for the system $\left(\mathrm{K}_{1 / 2} \mathrm{La}_{1 / 2}\right)_{0} \mathrm{Ba}_{1-x}$ $\mathrm{TiO}_{3}$. Parameter $x: 0.0 \cdot 1,0.2,00.3, \Delta 0.5, \Delta 0.7, \square 0.9, \times 1 \cdot 0$.

The second possibility is the presence of (i) Kanzig regions which are concerned with the influence of thermal osscillation (Kanzig 1951) (polarization fluctuations of this type are found to occur in pure perovskites but do not broaden the phase transitions significantly), or (ii) microscopic compositional inhomogeneities. The latter are submicron regions within which the compositions are held to be constant, but may vary from one region or 'microdomain' to another. Numerical estimates deduced from calculations made by Rolov (1965) for solid solutions of perovskite-like materials indicate that the linear dimensions of the microdomain may even be as small as $0.01 \mu$.

The other possibility is then the microscopic compositional variations. We believe that bulk compositional variations exist as a result of the disorder in the A cation site, and are responsible for the diffuseness of the dielectric peaks.

To illustrate, let us consider a composition where $x=0 \cdot 2$, consisting of two successive microdomains, each of linear dimensions $0.01 \mu$, that is each extended over $\sim 20$ unit cells. Then, in two microdomains (i.e., 40 unit cells) there will be $\left(\mathrm{M}_{1 / 2} \mathrm{La}_{1 / 2}\right)_{0.2} \mathrm{Ba}_{0.8} \mathrm{TiO}_{3} \times 40$ i.e. $4 \mathrm{La}^{3+}, 4 \mathrm{M}^{+}$and $32 \mathrm{Ba}^{2+}$ ions distributed over the A cation sublattice. The disorder in the lattice may permit the possibility of $3 \mathrm{La}^{3+}$ and one $\mathrm{M}^{+}$in the first microdomain and $1 \mathrm{La}^{3+}$ and $3 \mathrm{M}^{+}$in the neighbouring microdomain. Thus, bulk compositional variations are expected. It is reasonable to suppose, therefore, that a collection of microdomains, each having slightly different cation concentration, will result in a broadened crystal phase transition.

As the degree of disorder is maximum in the case of $\mathrm{Li}$, the spread of the dielectric peak with $(x=0 \cdot 2)$ in the $\mathrm{Li}$ series extends over several hundred 
degrees. In the case of $\mathrm{Na}$ and $\mathrm{K}$ series the spread occurred extended over a range of 100 degrees. The spread in the case of $K$ series is a little more than that of the $\mathrm{Na}$ series despite its lower degree of disorder and is expected to be due to the influence of disorder supplemented by the additional dipoles arising out of the vacant $K$ and $O$ sites.

\subsection{Dielectric relaxation in the potassium series}

As a result of $\mathrm{K}_{2} \mathrm{O}$ deficiency, interesting dielectric relaxations have been observed in the potassium series. The concentration of the $\mathrm{K}$-ion vacancies on the larger cation sublattice (calculated from unit cell dimensions) is presented in table 2 . It may be noted that $\left[V_{A}\right]=\frac{1}{2}\left[V_{\mathrm{o}}\right]$ where $\left[V_{A}\right]$ and $\left[V_{\mathrm{o}}\right]$ are concentrations of vacant $A$ and $O$ ion sites respectively.

The dielectric loss vs frequency measurements were made at $300 \mathrm{~K}$ using a Marconi bridge-TF 1245 and data are shown in table 2 and figure 4 . It may be noted here that no other dielectric loss anomalies are observed in the range starting from $100 \mathrm{~Hz}$ to $300 \mathrm{MHz}$ either in the $\mathrm{Na}$ or $\mathrm{K}$ series.

A linear relationship exists between the concentration of defects and loss tangent $\left(\tan \delta_{\max }\right)$ at the relaxation frequency. This is true for all samples except the extreme composition $\mathrm{K}_{1 / 2} \mathrm{La}_{1 / 2} \mathrm{TiO}_{3}(x=1 \cdot 0)$ which exhibits a broad relaxation behaviour.

According to Kingery (1960), the relaxation frequencies and defect concentrations, in the case of materials with discrete ion-jump relaxations, are $\sim 10^{3} \mathrm{~Hz}$ and $\sim 10^{17} / \mathrm{cm}^{3}$ respectively. Contrary to this, these parameters are $\sim 10^{6} \mathrm{~Hz}$ and $\sim 10^{20} / \mathrm{cm}^{3}$ in present titanates. Floyd (1964) has related such higher frequency relaxations to the migration of charged particles over several lattice sites through line defects (fractured surface). (By charged particle here is meant a particle with a non-zero effective charge at a given site). In the present system, for example, $\mathrm{La}^{3+}$ has one effective positive charge. This would be more when the number of oxygen ions (normally 12) in the coordination sphere of $\mathrm{La}^{3+}$ becomes less and less. Under such conditions, $\mathrm{La}^{3+}$ ion may migrate either through the line defects at the grain boundaries or to the neighbouring vacant A cation site through oxygen vacancies. On the basis of the absence of relaxation behaviour

Table 2. The dielectric relaxation data of the system $\left(\mathrm{La}_{1 / 2} \mathrm{~K}_{1 / 2}\right)_{3} \mathrm{Ba}_{1-} \mathrm{TiO}_{3}$.

\begin{tabular}{|c|c|c|c|}
\hline $\begin{array}{c}\text { Composition } \\
x\end{array}$ & $\begin{array}{c}\text { Defect con- } \\
\text { centration } \\
V_{A} / \mathrm{cm}^{3} \\
\left(\times 10^{-29}\right)\end{array}$ & $\begin{array}{c}\text { Frequency } \\
\text { maximum } \\
\log _{10} \omega\end{array}$ & $\tan \delta_{\max }$ \\
\hline 0.3 & $1 \cdot 4496$ & $7 \cdot 570$ & $0 \cdot 045$ \\
\hline 0.5 & $2 \cdot 8710$ & $7 \cdot 715$ & $0.0 \div 6$ \\
\hline $0 \cdot 7$ & $3 \cdot 5168$ & $7 \cdot 855$ & 0.047 \\
\hline 0.9 & $4 \cdot 6314$ & $8 \cdot 042$ & 0.051 \\
\hline $1 \cdot 0$ & $5 \cdot 1640$ & $8 \cdot 100$ & 0.085 \\
\hline
\end{tabular}




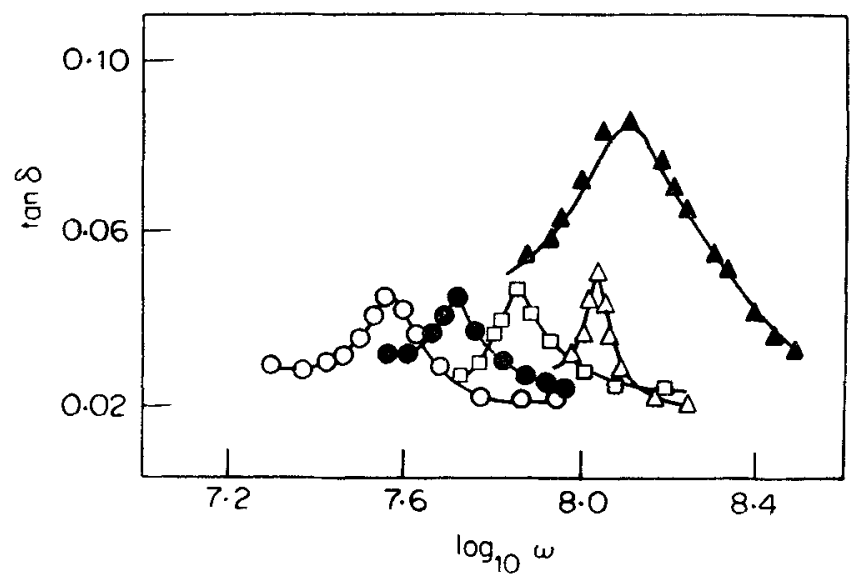

Figure 4. Dielectric loss tangent ( $\tan \delta$ ) versus frequency $\left(\log _{10} \omega\right)$ for the system $\left(\mathrm{K}_{1 / 2} \mathrm{La}_{1 / 2}\right)_{,} \mathrm{Ba}_{1-} \mathrm{TiO}_{3}$. Parameter $x: 00 \cdot 3,00.5, \square 0 \cdot 7, \Delta 0.9, \Delta 1 \cdot 0$.

observed in Na series we suppose that in the present system the relaxation is primarily governed by the migration of the charged particles through the vacant lattice sites within the bulk portion of the grains. This process is facilitated by the presence of oxygen vacancies $\left[V_{0}\right]$ in juxtaposition. The possible migration of $\mathrm{K}^{+}$ion is expected to be small or negligible because of its relatively larger crystal radius $r_{K}=1.74 \AA$ compared to that of $\mathrm{La}^{3+}\left(r_{\mathrm{La}}=1.46 \AA\right)$. The $\mathrm{Ba}^{2+}$ ion may also be assumed to be stationary, for (i) even in the presence of an oxygen vacancy, its effective charge is nearly zero at the $A$ site and (ii) its crystal radius is as large as that of $\mathrm{K}^{+}(1 \cdot 74 \AA)$. Here it may be noted that we have used the 12 coordinated radii of the cations as reported by Shanon and Prewitt (1969).

To account for the broadening of the relaxation peak in $\left(\mathrm{K}_{1 / 2} \mathrm{La}_{1 / 2}\right) \mathrm{TiO}_{3}$, where there are no stable $\mathrm{Ba}^{2+}$ ions, we have to presumably consider the possibility of more than one type of relaxation, for example the migration of oxygen ions too.

\subsection{Comparison of the dielectric properties}

Because of the striking similarity in the composition, structure and dielectric behaviour of the two series, we hope a critical comparison will enable us to understard (i) the effect of periodicity on the dielectric properties, anc (ii) other effects which may disturb the ferroelectric ordering. A brief account of the comparison follows.

In principle, as the average polarizability of the cross-substituted $A$ cations decreases in the order LiLa $\left(0.50 \times 10^{-24} \mathrm{~cm}^{3}\right)$, NaLa $\left(0.61 \times 10^{-24} \mathrm{~cm}^{3}\right)$, KLa $\left(0.93 \times 10^{-2} \mathrm{~cm}^{3}\right)$, we expect that their $T_{c}$ also follows the same order. The shape of the curve for the $x=0 \cdot 2$ composition in the $\mathrm{Li}$ series suggests that its Curie temperature may lie well below room temperature. The tetragonal samples of the $\mathrm{Na}$ series $(0 \leqslant x \leqslant 0 \cdot 3)$ exhibit ferroelectric ordering around room temperature, $308 \mathrm{~K}(x=0 \cdot 1), 305 \mathrm{~K}(x=0 \cdot 2)$ and $303 \mathrm{~K}(x=0 \cdot 3)$ (Varaprasad et al 1977), consistent with the medium polarisability values of NaLa. But the shapes of the curves for $x=0.1$ and 0.2 in the $\mathrm{K}$ series show that the $T_{\mathrm{c}}$ of these compositions is lower than that of the corresponding sodium compositions. On the 
basis of our studies on dielectric relaxations, it is recognised that the $\mathrm{K}_{2} \mathrm{O}$ deficiency in the potassium series would lead to a random array of the dipoles of the type say $\mathrm{La}^{3+}-V_{\mathbf{A}}^{2-}$ which in turn will destroy the long range ferroelectric ordering. Brout (1965) and Kanzig (1966) suggested that at low temperatures, the freezing in of the dipoles will give rise to a state of local order, and ferroelectric or antiferroelectric ordering may be observed under such low temperature conditions. Thus, the $\mathrm{K}_{2} \mathrm{O}$ deficiency may be invoked to account for the observed phenomena of $\mathrm{K}$ series having lower Curie temperatures than that of their sodium counterparts.

The unusually large tetragonality $(c / a=1.026)$ and the dielectric anomaly at about $400 \mathrm{~K}$ observed for the composition with $(x=0 \cdot 3)$ are not clearly understood. Possibly, the concentration of dipoles in this particular composition would have reduced to a critical value whereby local ordering occurs, and hence leads to structural distortions and dielectric anomalies.

\section{Conclusions}

The results of the above studies clearly indicate that (i) materials with high $T_{c}$ around room temperature can be obtained successfully by lowering the $T_{c}$ of $\mathrm{BaTiO}_{3}$ through the cross-substitution of $\mathrm{Ba}^{2+}$ by a $1: 1$ molar combination of tri- and monovalent ions, having an average polarizability less than that of $\mathrm{Ba}^{2+}$ and (ii) the broadening of the dielectric peak can be achieved by introducing disorder in the larger cation sublattice. The presence of the vacancies does not contribute to the broadening of the dielectric peak significantly. Thus, a rational approach to the design and synthesis of newer and potential dielectrics can be made through cross-substitution at the cationic sites in the model structure.

\section{References}

Blasse G 1977 J. Solid State Chem. 20217

Brous J, Fankuchen I F and Banks E 1953 Acta Crystallogr. 667

Brout R 1965 Phys. Rev. Lett. 14175

Clarke R and Burfoot J C 1974 Ferroelectrics 8505

Kaleveld E W, Bruntinek D J, Dotman J P and Blasse G 1973 J. Inorg. Nucl. Chem. 35 3928

Kanzig W 1951 Helv. Phys. Acta 24175

Kanzig W 1966 Magnetic resonance and relaxation (Proceedings of XIV colloque Ampere) (Amsterdam: North-Holland) p. 602

Kingery W D 1960 Introduction to ceramics (New York: John Wiley) p. 686

Pauling L 1960 Nature of the chemical bond 3rd ed. (Oxford of London and IBH Publishing Co) p. 548

Rolov B N 1965 Sov. Phys. Solid State 67 and 1676

Scott B A et al 1970 Mater. Res. Bull. 547

Shannon R D and Pewitt C T 1969 Acta Crystallogr. B25 925

Smolensky G A 1970 J. Phys. Soc. Jpn. 28 (Suppl.) p. 26

Varaprasad A M, Shashi Mohan A L, Biswas A B and Chakrabarty D K 1977 Phys. Stat. Sol. a44 787

Varaprasad A M, Shashi Mohan A L, Chakrabarty D K and Biswas A B 1979 J. Phys. C12 465 